\title{
Trombose de veia cava caudal em caprino: relato de caso
}

Laís Resende Paulino ${ }^{[a]^{*}}$, Rodolpho Almeida Rebouças ${ }^{[b]}$, Uila Almeida Aragão de Alcantara ${ }^{[c]}$, José Cláudio de Almeida Souza ${ }^{[d]}$, Jobson Filipe de Paula Cajueiro[ ${ }^{[e]}$, Carla Lopes de Mendonça[e] ${ }^{[e]}$ José Augusto Bastos Afonso ${ }^{[e]}$

\author{
[a] Programa de Residência em Sanidade de Ruminantes, Clínica de Bovinos, Universidade Federal Rural de Pernambuco \\ (UFRPE), Garanhuns, PE, Brasil \\ [b] Programa de Pós-Graduação em Ciência Veterinária, Universidade Federal Rural de Pernambuco (UFRPE), Recife, PE, Brasil \\ [c] Programa de Pós-Graduação em Sanidade e Reprodução de Ruminantes, Universidade Federal Rural de Pernambuco \\ (UFRPE), Garanhuns, PE, Brasil \\ [d] Unidade Acadêmica de Garanhuns (UAG), Universidade Federal Rural de Pernambuco (UFRPE), Garanhuns, PE, Brasil \\ [e] Clínica de Bovinos, Universidade Federal Rural de Pernambuco (UFRPE), Garanhuns, PE, Brasil
}

*Autor correspondente

e-mail: laispaulino@hotmail.com

\section{Resumo}

A trombose de veia cava caudal é uma síndrome clínica grave e fatal, associada a uma obstrução parcial ou completa da veia por um trombo. Esta afecção acomete normalmente bovinos adultos, em consequência à formação de abcessos hepáticos secundários à ruminite química nos casos de acidose ruminal crônica de origem alimentar. No entanto, não foram encontrados na literatura pesquisada relatos de trombose de veia cava caudal em pequenos ruminantes. Em virtude da ausência de dados, objetivou-se relatar um caso de trombose de veia cava em caprino. Um caprino, macho Saanem, 3 anos, com histórico de perda de apetite e apatia, foi atendido na Clínica de Bovinos, campus Garanhuns - UFRPE. Ao exame clínico, evidenciouse um estado pré-comatoso, decúbito lateral permanente, hipotermia $(35,9 \stackrel{\circ}{\circ} \mathrm{C})$, desidratação (10\%) e mucosas pálidas. Apresentava taquipneia, polipneia e dispneia expiratória acompanhada de gemidos, discreta sialorreia e hipomotilidade ruminal com discreta timpania. 0 abdômen possuía abaulamento bilateral, com tensão abdominal aumentada e som de líquido ao balotamento do antímero direito. Nos exames complementares, a ultrassonografia abdominal revelou grande quantidade de conteúdo anecóico deslocando as vísceras aproximadamente 10 centímetros dorsalmente, sugerindo acúmulo de líquido, com presença de estruturas filamentosas e hiperecóicas (fibrina). A análise do líquido peritoneal revelou transudato modificado, e avaliação hematológica revelou anemia grave de caráter regenerativa, leucocitose 
expressiva por neutrofilia com desvio à esquerda regenerativo, e hipoproteinemia. Devido à gravidade dos sinais clínicos, o animal veio a óbito durante a realização dos exames. Na necropsia, observou-se grande quantidade de líquido amarelo, turvo e com debris de fibrina na cavidade abdominal, fígado de consistência endurecida, em aspecto de noz moscada e com acentuação do padrão lobular. Foi constatada a presença de um trombo $( \pm 10 \mathrm{~cm})$ com coloração branco-amarelada, seco e friável, que encontrava-se ocluindo difusamente o lúmen da veia cava caudal próximo ao fígado. Neste local havia grande quantidade de conteúdo de aspecto purulento, que também se estendia para a região torácica da veia cava caudal. Além disso, apresentava uma pneumonia tromboembólica com uma área focal de conteúdo caseoso de coloração amarela $(5 \times 5 \mathrm{~cm})$ no lobo caudal esquerdo do pulmão. Neste caso, embora não haja relatos na literatura sobre a ocorrência de trombose de veia cava caudal em caprinos, a partir do histórico do animal é possível afirmar que a síndrome pareceu derivar da alimentação com elevada densidade energética em que estava sendo submetido, assim como ocorre em vacas em lactação ou bovinos em regime de engorda que recebem dietas com características semelhantes. 